\section{NUMERICAL ANALYSIS AND OPTIMIZATION OF THE HOOK FORGING PROCESS}

\author{
JAN RIHACEK, JAN BARTAK, KAMIL PODANY, MICHAELA \\ CISAROVA, EVA PETERKOVA
}

Brno University of Technology, Faculty of Mechanical Engineering, Institute of Manufacturing Technology, Brno, Czech Republic

DOI : 10.17973/MMSJ.2021_6_2021010

e-mail: rihacek.j@fme.vutbr.cz

The paper is focused on analysis and optimization of the jaw turnout lock hook forging process, which is used in rail transport. It is forged from $37 \mathrm{MnSi5}$ steel in Kralovopolska LLC. Currently, a fold occasionally occur in the inner side of curved part formation during the forging process, which leads to possible cracks in the finished forged part in some cases. Therefore, optimized semi-finished product size and tool geometry is proposed and subsequently verified by numerical simulation using Simufact Forming software. Before the actual optimization, an accuracy of the simulation is verified by analyzing of the current state and comparing simulation results with the real state.

KEYWORDS

FEM, FVM, numerical simulation, Simufact Forming, 37MnSi5 steel

\section{INTRODUCTION}

The solved part is the hook of the jaw exchange lock. Mentioned hook with the main dimensions is shown in Fig. 1. It is manufactured in Královopolská LLC by using hot forming technology. There are no sharp edges on the forged part and all roundings are at least $3 \mathrm{~mm}$ in the size. $\mathrm{In}$ the direction of the forging, a 1:10 taper of surfaces is performed.
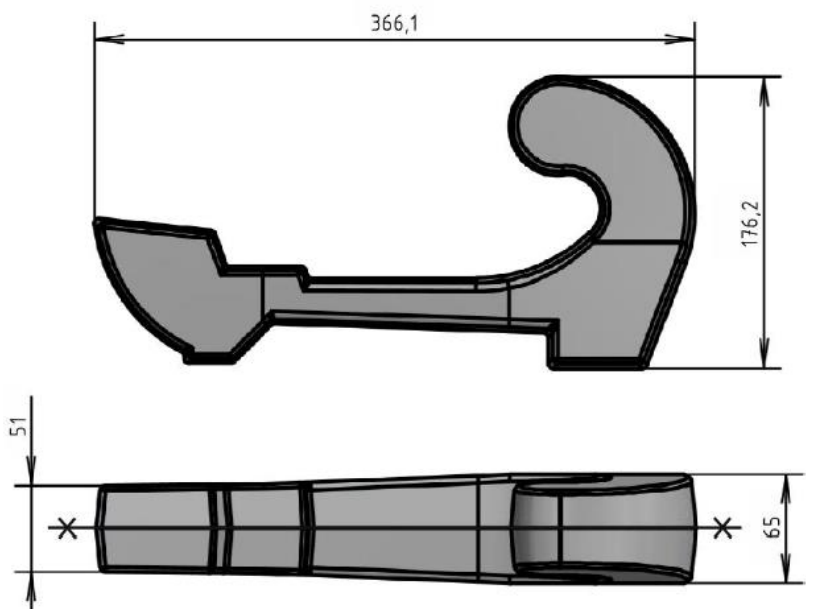

Figure 1. Jaw turnout lock hook [Bartak 2020]

The hook of the jaw exchange lock is used in railway transport as part of the switch mechanism. The hook is screwed to the rail tongue over the mast. The tongue forms an area into which the rail wheel is placed and thus the wheel is "forced" to turn to another track. Therefore, it is highly stressed component, whose quality should always be guaranteed.

The material, which is used for the hook production is $37 \mathrm{MnSi} 5$ steel. Mentioned Mn-Si steel is suitable for tempering, although it is susceptible to tempering brittleness. [Bartak 2020]
Main mechanical properties and chemical composition of $37 \mathrm{MnSi} 5$ steel are summarized in Tab. 1 and Tab. 2.

\begin{tabular}{|l|l|l||l|}
\hline Yield stress & $\mathrm{R}_{\mathrm{e}}$ & {$[\mathrm{MPa}]$} & 540 \\
\hline Ultimate strength & $\mathrm{R}_{\mathrm{m}}$ & {$[\mathrm{MPa}]$} & $780-930$ \\
\hline Young's modulus & $\mathrm{E}$ & {$[\mathrm{GPa}]$} & 206 \\
\hline Shear modulus & $\mathrm{G}$ & {$[\mathrm{GPa}]$} & 79 \\
\hline Ductility & $\mathrm{A}_{5}$ & {$[\%]$} & 14 \\
\hline Relative contraction & $\mathrm{Z}$ & {$[\%]$} & 45 \\
\hline
\end{tabular}

Table 1. Mechanical properties of $37 \mathrm{MnSi5}$ steel [Bartak 2020]

\begin{tabular}{|c|c|c|c|c|}
\hline$\% \mathrm{C}$ & $\% \mathrm{Mn}$ & $\% \mathrm{Si}$ & $\% \mathrm{P}$ & $\% \mathrm{~S}$ \\
\hline \hline $0.33-$ & $1.1-1.4$ & $1.1-1.4$ & $\max$. & $\max$. \\
\hline
\end{tabular}

Table 2. Chemical composition of $37 \mathrm{MnSi} 5$ steel [Bartak 2020]

Currently, the part is manufactured by using hot forming technologies of cogging, bending, closed die forging and trimming:

- cutting the material with a band saw from a semi-finished product of square cross-section $80 \times 80 \mathrm{~mm}$, to a length of $329 \mathrm{~mm}$ (weight of $16.5 \mathrm{~kg}$ ),

- heating of the semi-finished product in a gas furnace at a temperature of approximately $1150^{\circ} \mathrm{C}$ for 30 minutes,

- production of a preform by cogging in hammer ABUS 1000,

- bending of the workpiece on the crank press LKD 520,

- preliminary forging in the counter-rotating hammer Beche 16,

- trimming of the forged part in the trimming tool using press LKD 520,

- final forging (calibration) in the counter-rotating hammer Beche 16, where the part is formed to the required shape and dimensions,

- final trimming operation (press LKD 520).

During the production process, a problem arises in the form of the fold on the inside area of the hook bent part, see Fig. 2 . In some cases, it is possible to remove the resulting defect by regrinding the surface to the lower limit of the manufacturing tolerance. Predominantly, it causes cracks that are dangerous for the function of the hook. Therefore, it has to be removed. [Bartak 2020]

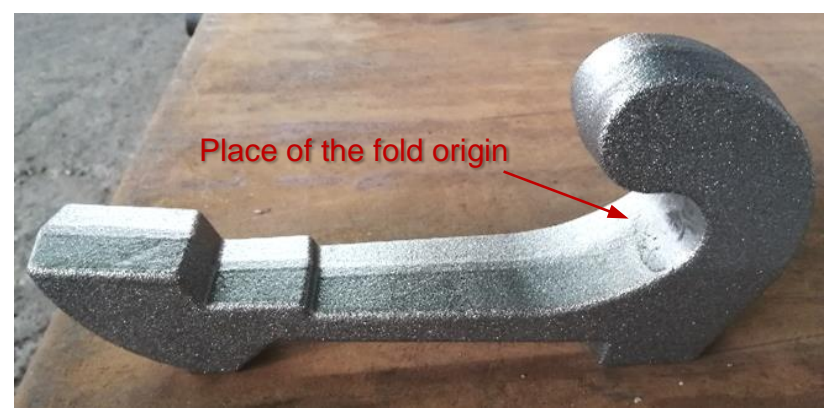

Figure 2. Forged part [Bartak 2020]

\section{USING OF NUMERICAL SIMULATION}

The main prerequisite for the use of numerical simulations in the forging process is the verification of the proposed manufacturing system before the production itself. Ideally, designed and real manufactured shapes should be matched for forging stages with simulation model. It is clearly evident, that the match will not always be $100 \%$, already due to the nature of the numerical calculation. However, it is important to be able to assess how far these deviations are acceptable in terms of manufacturability. In this case, two approaches to the solution were used, i.e. the finite element method (FEM) and also the finite volume method (FVM), see basic principles in Fig. 3. [Bartak 2020] 


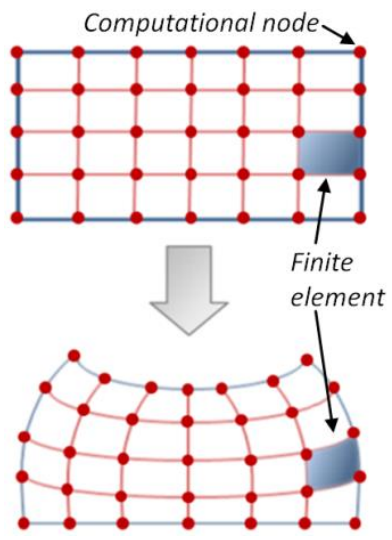

a) finite element method

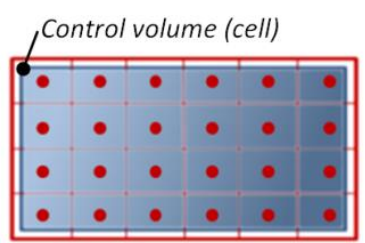

Computational node (centroid)

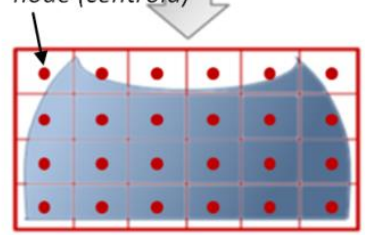

b) finite volume method
Figure 3. Basic schemes of FE and FV methods [Buijk 2008]

FEM is generally more accurate, but the calculation takes a disproportionately long time for more complex simulations, which is one of the main disadvantages of this method. From this point of view, it is suitable to use FVM for hot forming (especially for closed die forging). Although FVM does not achieve such accuracy as FEM, it has proved successful for the mentioned application. Therefore, FEM solution was used for heating, cogging, cooling and bending. Forging operation was realized by using FVM. [Buijk 2008], [Simufact 2019]

Material properties of the forged material must take into account the different forging temperature as well as the strain rate, which is especially important for hammer forging. In this case, the Hensel-Spittel model was chosen to determine the flow stress. It is used to describe the flow stress curves in the whole range of deformations, depending on the temperature, strain and strain rate:

$$
\begin{aligned}
\sigma_{p}= & A \cdot e^{m_{1} \cdot T} \cdot T^{m_{8}} \cdot \varphi^{m_{2}} \cdot e^{\left(\frac{m_{4}}{\varphi}+m_{6} \cdot \varphi\right)} \cdot(1+\varphi)^{m_{5} \cdot T} . \\
& \cdot \dot{\varphi}^{m_{3}+m_{7} \cdot T}
\end{aligned}
$$

where $\sigma_{\mathrm{p}}$ is the flow stress [MPa], $\varphi$ is the effective strain [-], $\dot{\varphi}$ is the strain rate $\left[\mathrm{s}^{-1}\right], \mathrm{T}$ is the temperature $\left[{ }^{\circ} \mathrm{C}\right], A$ and $\mathrm{m}_{1}, \mathrm{~m}_{2}, \mathrm{~m}_{3}$, $m_{4}, m_{5}, m_{6}, m_{7}$ and $m_{8}$ are the material coefficients [-].

The coefficients used in the material model for $37 \mathrm{MnSi} 5$ steel are shown in tab. 3. In this case, the material model takes into account constants $A, m_{1}, m_{2}, m_{3}$ and $m_{4}$. The other material coefficients are zero. For the mentioned steel, the individual flow stress curves are shown in Fig. 4 for a constant strain rate of $10 \mathrm{~s}^{-1}$. [Forejt 2004], [Simufact 2019]

\begin{tabular}{|c|c|c|c|c|}
\hline $\mathrm{A}$ & $\mathrm{m}_{1}$ & $\mathrm{~m}_{2}$ & $\mathrm{~m}_{3}$ & $\mathrm{~m}_{4}$ \\
\hline \hline 1858.43 & -0.0029 & -0.14227 & 0,14102 & -0.05764 \\
\hline
\end{tabular}

Table 3. Coefficients of Hensel-Spittel model for 37MnSi5 steel

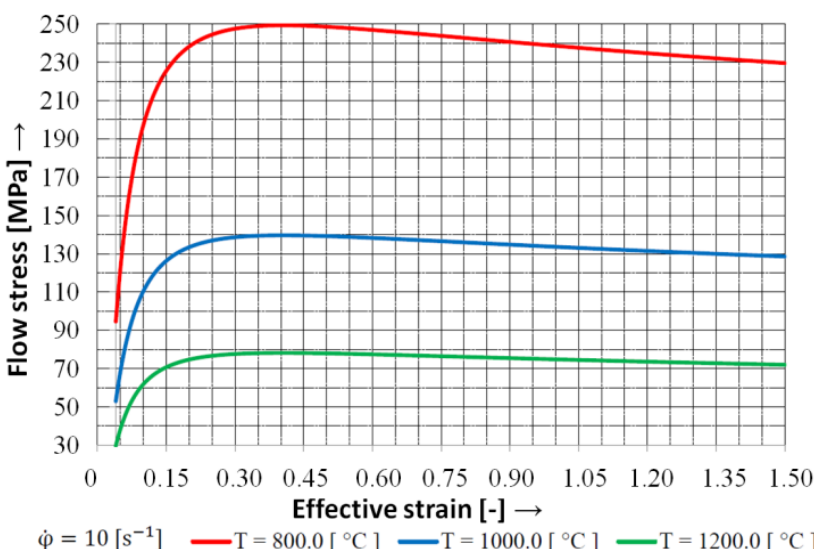

$\dot{\varphi}=10\left[\mathrm{~s}^{-1}\right]-\mathrm{T}=800.0\left[{ }^{\circ} \mathrm{C}\right]-\mathrm{T}=1000.0\left[{ }^{\circ} \mathrm{C}\right]-\mathrm{T}=1200.0\left[{ }^{\circ} \mathrm{C}\right]$

Figure 4. Flow stress of $37 \mathrm{MnSi} 5$ steel
In the simulation, these data are supplemented by a description of elastic properties using the Young's modulus $\mathrm{E}=206 \mathrm{GPa}$ and Poisson ratio $\mu=0.3$. [Sigmund 2019]

Friction model is described according to the lubricant type, which is based on water without graphite particles or mineral oils. A combined friction model was chosen, which combines the Coulomb and the Shear friction law. After consultation with Simufact Forming software support, the coulomb friction coefficient was chosen as 0.3 and interface friction factor for the description of the Shear friction was set to $m=0.4$. Other important simulation parameters are listed below:

- ambient temperature $\mathrm{T}_{\mathrm{A}}=20^{\circ} \mathrm{C}$,

- semi-finished heating temperature $\mathrm{T}_{0}=1150^{\circ} \mathrm{C}$

- preheating of forging die cavities $\mathrm{T}_{\mathrm{D}}=350^{\circ} \mathrm{C}$,

- other tool temperature $\mathrm{T}_{\mathrm{T}}=150^{\circ} \mathrm{C}$,

- heat transfer coefficient to environment $\alpha=50 \mathrm{~W} \cdot \mathrm{m}^{-2} \cdot \mathrm{K}^{-1}$,

- cooling times during the transport of the semi-finished product between operations were considered 2 to 5 seconds, depending on the distance between machines.

The geometric model of the simulation with the setting of tools for main production steps of the current state is shown in Fig. 5. Ideally rigid tools with heat transfer realization were considered.

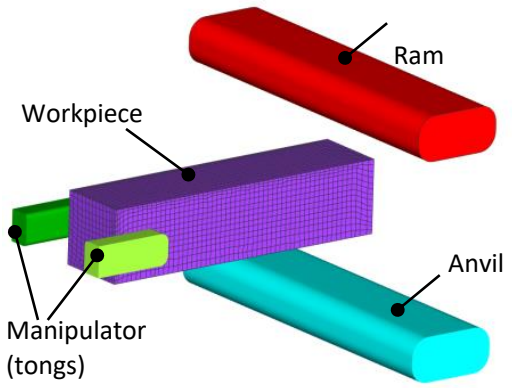

a) cogging operation

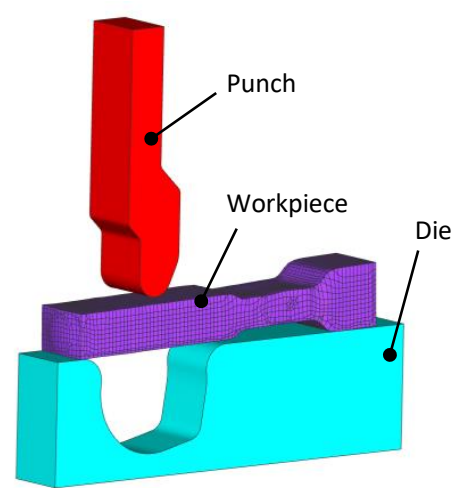

b) bending operation

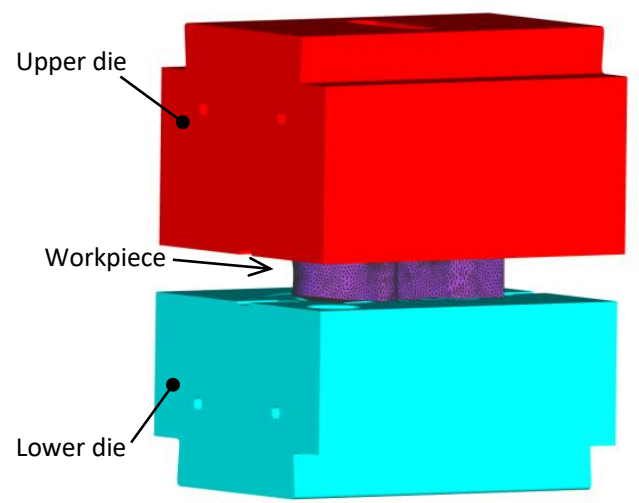

c) forging operation

Figure 5. Geometrical model of the FEM analysis 


\section{SIMULATION OF THE CURRENT STATE}

After performing a set of numerical simulations, it is possible to focus on the results evaluation. The individual partial results of the simulations, for the production operations corresponding to the production process mentioned above, are shown in Fig. 6 . In this case, the figure represents the distribution of the plastic deformation over the formed part.
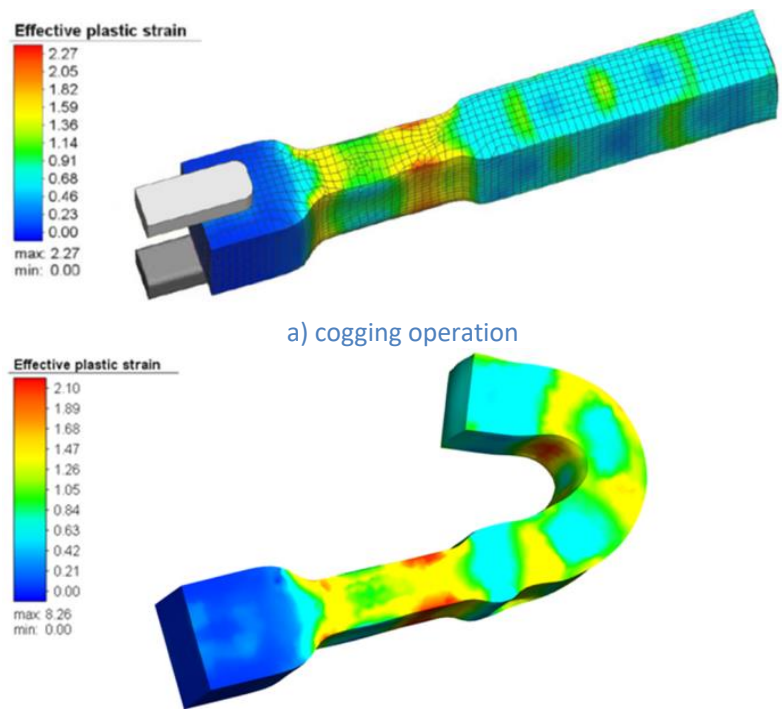

b) bending operation

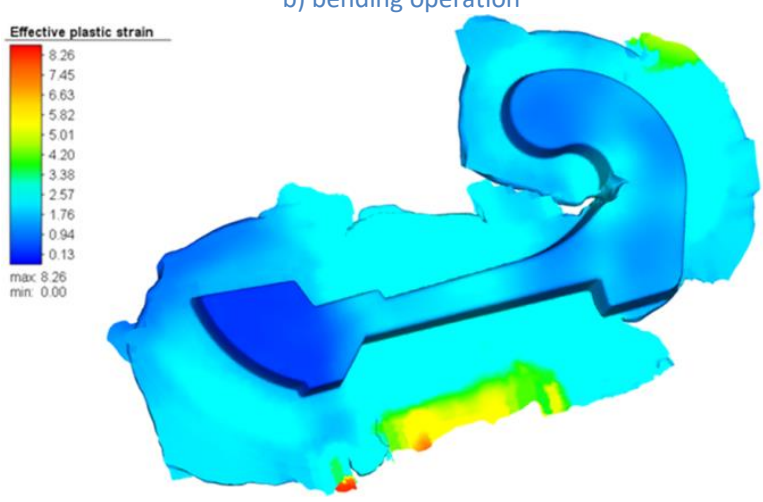

c) preliminary forging operation

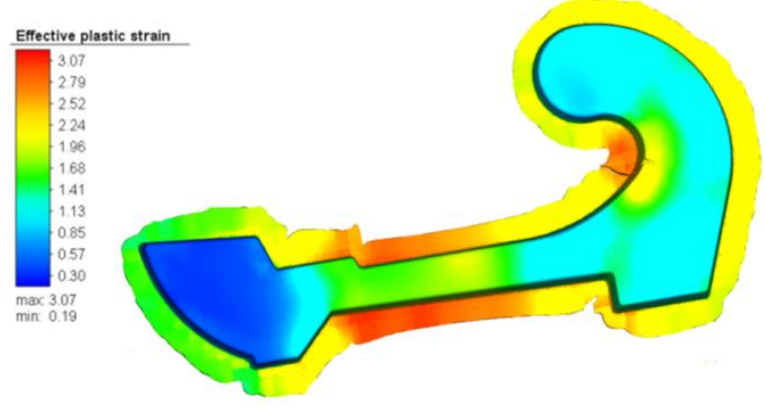

d) final forging operation (shape calibration)

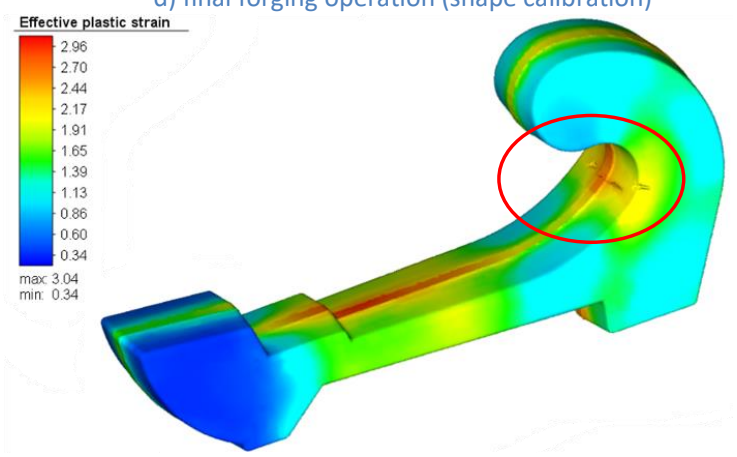

e) final shape of the forged part after trimming
After heating in the gas furnace, the preform is produced by cogging in hammer ABUS 1000 in the first step, see Fig. 6a. The central portion has a height of $40 \mathrm{~mm}$ and a length of $135 \mathrm{~mm}$. The wider part of the preform, which is bent in the following operation, has a height of $60 \mathrm{~mm}$ and a length of $250 \mathrm{~mm}$.

The next technological operation is bending in the bending tool mounted in the crank press LKD 520, see Fig. 6b. It is important to note, that partial problems already occur at this stage, because the shape of the bend is not quite optimal, i.e. it does not correspond exactly to the die cavity in the next operation, which is the preliminary closed die forging (Fig. 6c).

For the mentioned operation, the method of simulation was changed from FEM to FVM, mainly due to the acceleration of the calculation. As it is evident from the result, a certain part of the forging section remains unfilled at the end of the forging process due to the poor material flow in the die cavity and also in the flash gutter.

After trimming, the calibration closed die forging is performed by only one blow of the hammer. As can be seen from Fig. 6d, the unfilled section in the curved part of the forging healed during the calibration process. However, the fold was created at this place. The maximum depth of the fold from the part surface is over $6 \mathrm{~mm}$ and its total length exceeds $42 \mathrm{~mm}$. After trimming operation, the fold is still visible on the forging body, as it is shown in Fig. 6e.

After comparing the simulation result with a real forged part, which is shown in Fig. 7, it is clear that the analysis of the current state based on FEM and FVM shows quite good agreement with reality. The location, appearance and size of the defect were confirmed.

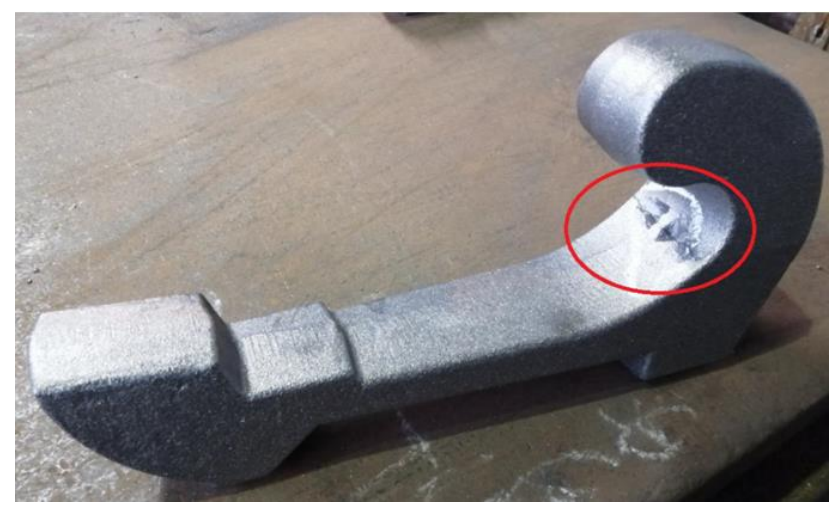

Figure 7. Real forged part after trimming operation [Bartak 2020]

\section{PROCESS OPTIMIZATION}

Based on the information, which were obtained during the simulation of the current state, the optimization of the manufacturing process was performed. In the beginning, it is necessary to determine the appropriate volume of the semifinished product, because too much of it causes a problem, as it is also evident from the need to trim the forging twice during production.

Firstly, the forged part volume with the necessary additions was determined according to [Elfmark 1992], which is $1,464,214 \mathrm{~mm}^{3}$, which corresponds to $11.5 \mathrm{~kg}$. Based on characteristic cross section (Fig. 8a), which take into account a distribution of material volume in the final forging using numerous cross sections of the forging with calculated volumes, shape of the ideal preform was found with constant width of 80 $\mathrm{mm}$ along the entire length, see Fig. 8b. [Lenfeld 2016] 


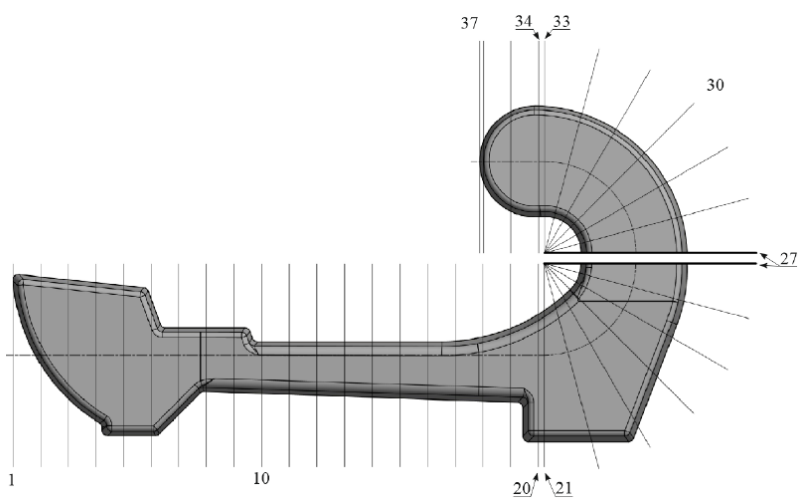

a) schematic view of characteristic cross sections

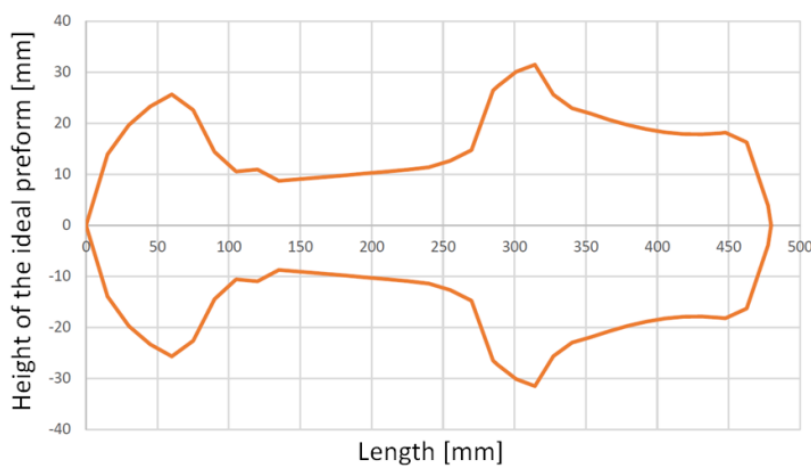

b) ideal preform shape

Figure 8. The ideal preform shape determination [Bartak 2020]

In the next, the ideal preform shape was transformed for initial blank dimensions of $75 \times 75 \times 270 \mathrm{~mm}$ into the proposal of the real preform, which is shown in Fig. 9 .

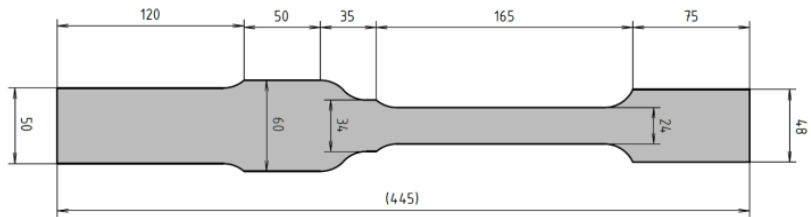

Figure 9. The ideal preform shape determination

Furthermore, after bending and forging stages, some unfilled sections appear at the forged part, as can be clearly seen from Fig. 10.

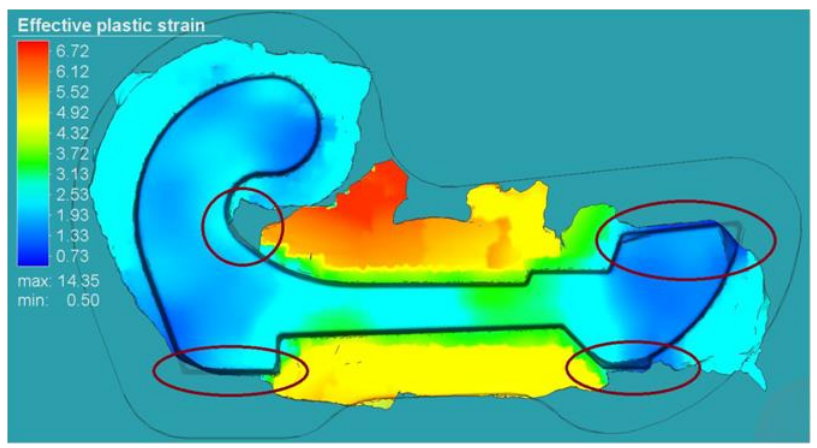

Figure 10. The ideal preform shape determination

Therefore, it was necessary to to modify the preform shape according to the simulation results (material flow determination) to the final design (Fig. 11) with its final weight of $11.9 \mathrm{~kg}$. In the following, dimensions of the initial blank $75 \times 75 \times 270 \mathrm{~mm}$ are considered. Compared to the ideal preform shape, its width is not constant along the length, but variable. It is an easier option how to correct the amount of material needed to fill the die cavity.
The preform is more divided in the direction of its height in order to prevent the formation of folds in places with greater difference in its height.

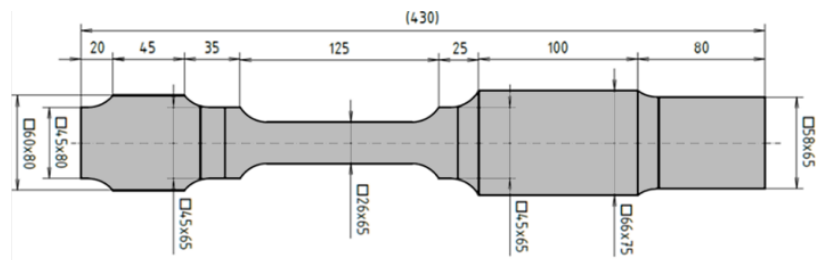

Figure 11. The ideal preform shape determination

It was also necessary to optimize the shape of the tools for bending and forging. The principle of the bending tool was taken from the existing production method. However, its geometry has been changed to make the bent part more suitable in shape. A modified bending tool assembly is shown in Fig. 12. A rounding at the end of the punch is the same, as in the case of the current status, i.e. radius of $25 \mathrm{~mm}$, but its transition to the straight section is made with a gradual rounding of $90 \mathrm{~mm}$ instead of the straight connection, which is in the current tool shape. This solution makes the bending point more similar to the final forging and helps to prevent origin of the fold.

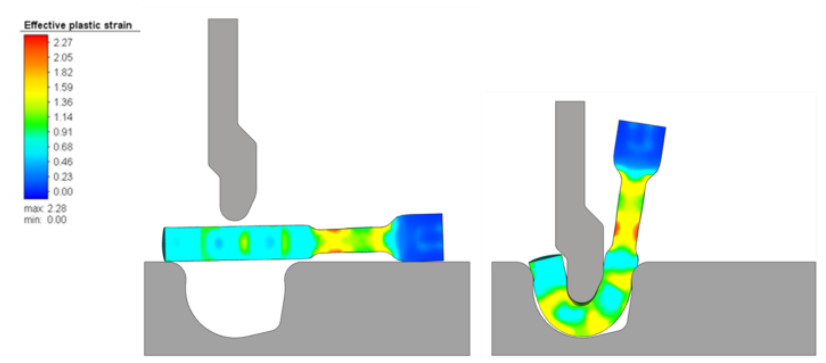

a) current status

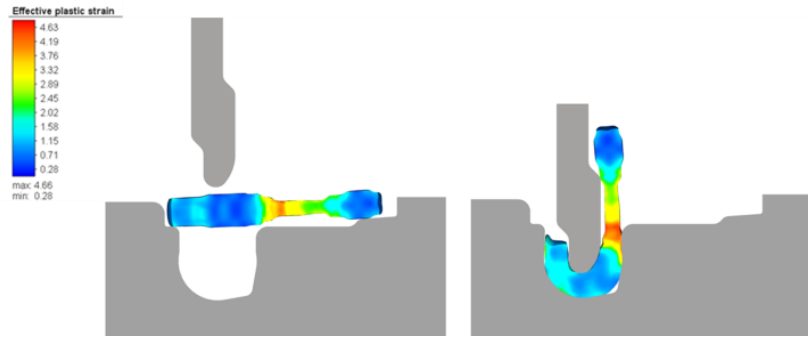

b) optimized shape

Figure 12. Bending optimization

If the preform shape and bending process are optimized, then only one forging operation is sufficient to achieve the desired shape of forged part. Forging dies was proposed based on standards ČSN 22 8308, ČSN 21 1414, ČSN 21 1410, ČSN 211416 and it is based on the die design, which is already used for final forging operation (calibration). The basic characteristics of dies are briefly listed below (see Fig. 13):

- flash land: height $h_{1}=2 \mathrm{~mm}$ and width $w_{1}=10 \mathrm{~mm}$,

- flash gutter: height $h_{g}=4 \mathrm{~mm}$ and width $\mathrm{w}_{\mathrm{g}}=28 \mathrm{~mm}$,

- outer die dimensions: length $\mathrm{L}=630 \mathrm{~mm}$, width $\mathrm{W}=610 \mathrm{~mm}$, height $\mathrm{H}=400 \mathrm{~mm}$,

- tool guide: realized by two pins with a diameter of $90 \mathrm{~mm}$ placed diagonally in the lower die (distance of the guide pin from the die edge $a_{p}=85 \mathrm{~mm}$ ),

- parting line interface: $S_{p}=2732 \mathrm{~cm}^{2}$ (a minimum of $300 \mathrm{~cm}^{2}$ per 1 ton of ram weight is required to prevent dies from upsetting when dissipating excess energy, which is certainly fulfilled),

- preheating temperature $T_{p}=350^{\circ} \mathrm{C}$. 


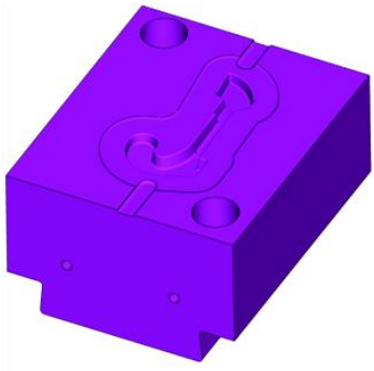

a) current status

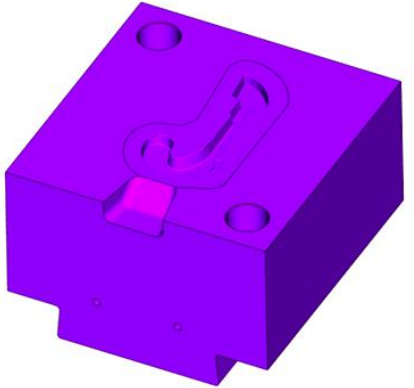

b) optimized shape
Figure 13. Geometry of the lower forging die

In the case of an optimized tool, three hammer blows are required to forge, as it is shown in Fig. 14. The trimming of the flash is performed in the same tool as is currently used.
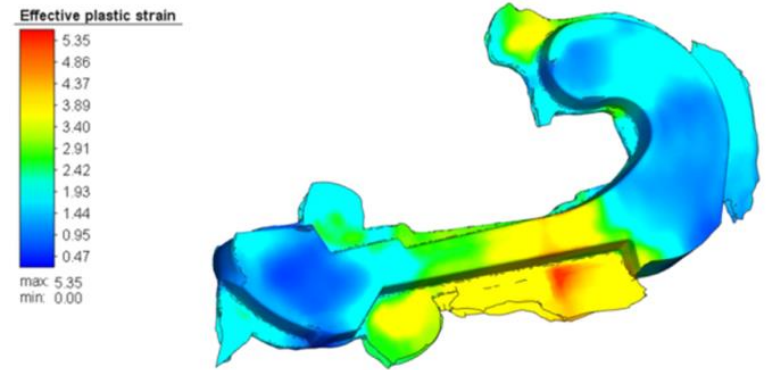

a) first blow
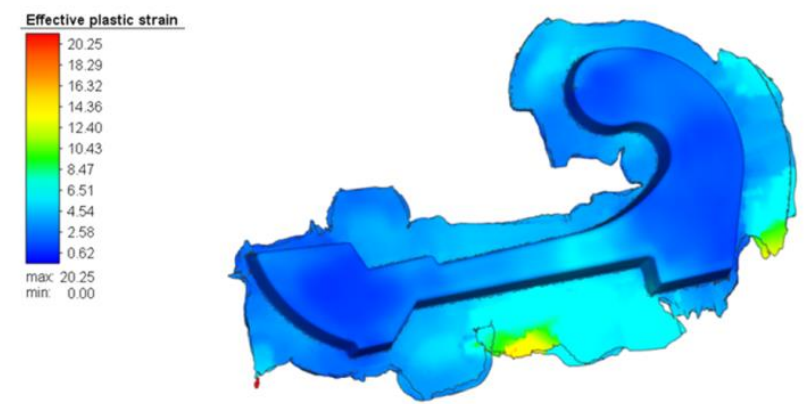

b) second blow
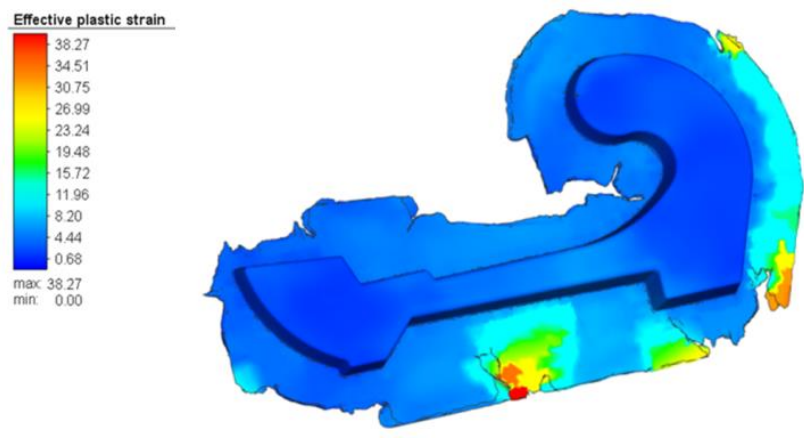

c) third blow
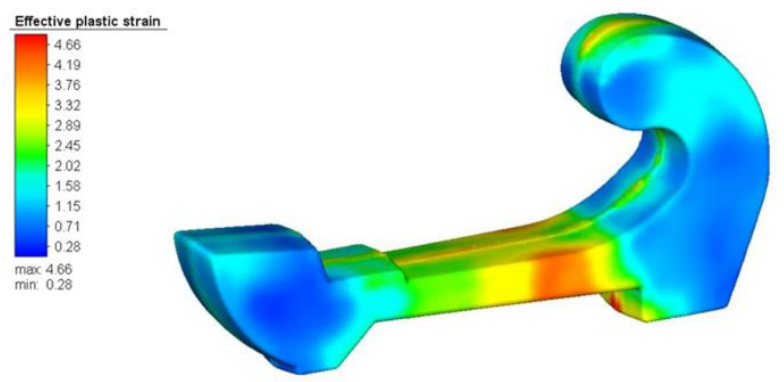

d) after trimming

Figure 14. Effective plastic strain during the optimized forging process
As can be seen from the simulation results, the new die design no longer causes the problematic fold. When the "Possible fold/lap" module is switched on in the Simufact Forming software, it is possible to display the probable occurrence of folds in forged part. As can be seen in Fig. 15, the calculation detected some folds, but they are located only in the area of the trimmed flash.

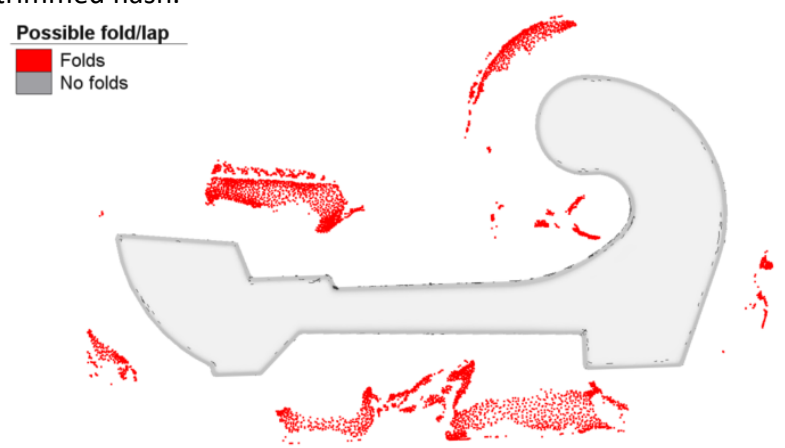

Figure 15. Fold detection analysis at the end of forging process

The resulting temperature after forging of the hook is in the range of 1060 to $750{ }^{\circ} \mathrm{C}$. The lowest temperature is found only on the surface of the forging, mainly on its rounded edges, which are in contact with the bottom die during the entire forging process, see Fig. 16. However, the forging did not cool down to this temperature until the last blow, when its edges were no longer deformed and the temperature did not rise. The complete forging of the hook was carried out already during the beginning of the third blow, and therefore it was not necessary for the metal to have a higher temperature in these places at the end of the forging process.
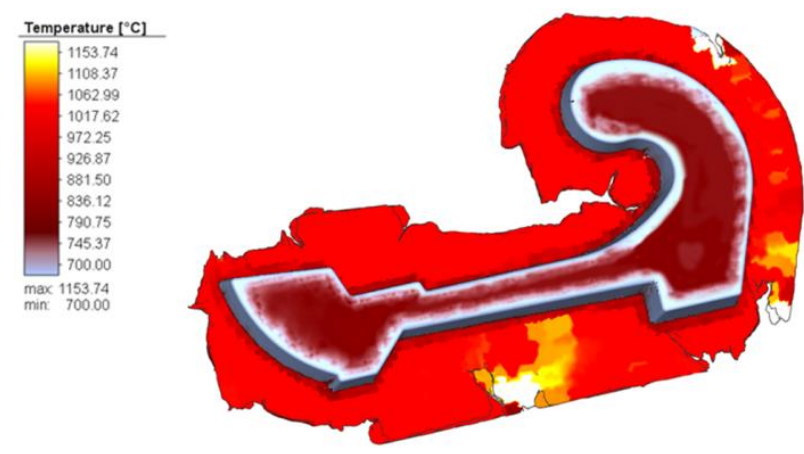

Figure 16. Temperature distribution before trimming operation

\section{CONCLUSIONS}

In this paper, the optimization study of the jaw turnout lock hook forging process was performed. The main reason for optimization of the part was the fold creation on the inside of the curved end of the hook. By creating a numerical simulation of the current state in the Simufact Forming software, results were obtained which were compared with real production. Thus, the accuracy of the numerical calculation was verified and at the same time the conditions under which the hook is forged were analyzed. It has been found that the geometry of the bending tool and forging dies is not suitable for the production of a hook. In addition, the volume of the semi-finished product is too large for the current state of production. The analysis showed that the geometry of the bending tool and forging dies is not suitable for the production of the hook. In addition, the volume of the preform is too large for the current state of production.

Therefore, based on the identified parameters, the production process was optimized, taking into account the use of the same 
machinery. It was necessary to determine the appropriate volume of material depending on the flash groove dimensions, heating method, etc. The calculated weight of the semi-finished product was $11.5 \mathrm{~kg}$. However, in subsequent numerical analyzes, it was found that the calculated volume of material is insufficient for complete hook forging. Due to this problem, the dimensions and shape of the preform have been modified. The final weight of the blank for the optimized process was thus set at $11.9 \mathrm{~kg}$. The preform optimization results in a significant saving of material compared to the current status, which is $4.6 \mathrm{~kg}$. Based on the results of numerical simulations, a new concept of bending tools and forging dies was subsequently designed with the reduction of the number of forging and cutting operations to only one, which is a significant saving not only in terms of total production time.

The results from numerical simulations confirmed that adjustments to the size of the preform and the geometry of the tools will ensure forging of the hook without folds or other defects that could cause a loss of safety or functionality of this product. It is clear that due to the free manual forging at the beginning of the forging process, optimization is somewhat problematic in terms of repeatability, but even when considering this effect, the benefit is unquestionable.

\section{ACKNOWLEDGMENTS}

The paper was supported by project "Analysis of formability and weldability of materials produced by 3D wire metal printing" within the specific research of Faculty of Mechanical Engineering, Brno University of Technology relating to the grant no. FSI-S-20-6336.

\section{REFERENCES}

[Bartak 2020] Bartak, J. (In Czech). Analysis of a Forging Process of the Jaw Turnout Lock Hook. Brno: Brno University of Technology, 2020. (In Czech)

[Buijk 2008] Buijk, A. J. Finite Volume and Finite Element Integration in Simufact Forming. Simufact-Americas LLC, 2008, United States [online]. 12. 2. 2015 [22. 2. 2020]. Available from <https://www.mscsoftware.com/sites/default/files/2008.1_Fini te_Volume_and_Finite_Element_Integration_in_SimufactFormi ng.pdf >

[Elfmark 1992] Elfmark, J. Metal Forming. Prague: SNTL, 1992. ISBN 80-03-00651-1 (In Czech)

[Lenfeld 2016] Lenfeld, P. Technology II. Liberec: TU in Liberec, 2016. ISBN 978-80-7494-304-1 (In Czech)

[Forejt 2004] Forejt, M. et al. Estabilishing the dynamic mechanical properties of materials by the hopkinson test method. Acta Mechanica Slovaca, 2004, Vol. 8, No. 2b,pp 93-98, ISSN: 1335-2393

[Sigmund 2019] Sigmund, M. Plasma overlay welding of cobalt alloy. MM Science Journal, October 2019, Vol. 2019, No. 3, pp 2982-2986. ISSN 1803-1269

[Simufact 2019] Simufact Engineering GmbH. Simufact Forming

\section{CONTACTS:}

Ing. Jan Rihacek, Ph.D., Ing. Jan Bartak, Ing. Kamil Podany, Ph.D., Ing. Michaela Cisarova, Ph.D., Ing. Eva Peterkova, Ph.D., Brno University of Technology, Faculty of Mechanical Engineering, Institute of Manufacturing Technology, Department of Metal Forming and Plastics Technicka 2896/2, Brno, 616 69, Czech Republic e-mail: rihacek.j@fme.vutbr.cz 